\title{
Research Progress in Preparation and Purification of Rare Earth Metals
}

\author{
Hang Liu ${ }^{1}$, Yao Zhang ${ }^{2}$, Yikun Luan ${ }^{1, *}$, Huimin $\mathrm{Yu}^{3}$ and Dianzhong $\mathrm{Li}^{1}$ \\ 1 Institute of Metal Research, Chinese Academy of Sciences, Shenyang 110016, China; \\ liuhang@imr.ac.cn (H.L.); dzli@imr.ac.cn (D.L.) \\ 2 Baotou Rare Earth R\&D Center, Chinese Academy of Sciences, Baotou 014000, China; zhangyao@btzkxt.cn \\ 3 School of Metallurgy, Northeastern University, Shenyang 110819, China; hmyu@ire.ac.cn \\ * Correspondence: ykluan@imr.ac.cn
}

Received: 28 August 2020; Accepted: 9 October 2020; Published: 15 October 2020

check for updates

\begin{abstract}
The purity of rare earth metals is one of the most important factors to research and develop high technique materials. However, high purity rare earth metals are not easily achieved. This review summarizes the preparation and purification methods of rare earth metals. First, the preparation principle and process of molten salt electrolysis and metal thermal reduction are introduced. The main sources of metallic impurities and interstitial impurities in rare earth metals as well as the action mechanism of reducing the concentration of different impurities are analyzed and summarized. Then, the purification principle and process of vacuum distillation, arc melting, zone melting, and solid state electromigration are also discussed. Furthermore, the removal effect and function rule of metallic impurities and interstitial impurities in rare earth metals are outlined. Finally, the crucial issues in the development of high purity rare earth metals are put forward, and the development direction of high purity rare earth metals in future are pointed out on this basis.
\end{abstract}

Keywords: rare earth metals; purity; impurity concentration; preparation; purification

\section{Introduction}

Rare earth element (named as RE) is the general name of 17 special elements, containing lanthanide element, scandium, and yttrium. They have been widely applied in functional materials, steel, and nonferrous metals because of their special optical, electrical, and magnetic properties. In particular, RE functional materials and structure materials play an important role in the development of aerospace industry, military equipment [1], domestic appliances [2], new energy saving, and environmental technologies [3,4]. For example, neodymium and samarium are the main components of $\mathrm{NdFeB}$ permanent magnets and SmCo permanent magnets respectively. Furthermore, magnetic energy product of RE permanent magnet materials is much higher than that of ferrite and Al-Ni-Co permanent magnet materials [5,6]. Therefore, RE permanent magnet materials have been proverbially used in air conditioning, sound box, and permanent magnet motor. Terbium and dysprosium are the main ingredients of magnetostrictive materials, and the magnetostrictive coefficient is superior than that of Fe-Ni-Co alloy. In addition, RE magnetostrictive materials have been widely used in high-power emitting sonar, sensor, and communications. RE hydrogen storage alloy shows the advantages of high electric capacity, good stability, high hydrogen absorption efficiency, and no pollution, which makes it to be widely used in the fields of battery, brake, and refrigeration [7]. The addition of rare earth to steel can modify inclusions, refine grain, and strengthen microalloying, which can significantly improve the fatigue performance of bearing steel [8]. The purity of rare earth metals is the key factor affecting the performance of functional materials and structural material. For example, high oxygen concentration of rare earth metals could weaken the intrinsic coercivity of RE permanent magnet 
materials. Low purity rare earth metals may cause nozzle clogging and unstable performance in continuous casting process of RE steel. Specially, magnetostrictive materials and sputtering target materials require the purity of rare earth metals to be higher than $99.99 \%[9,10]$. The purity of rare earth metals should exceed $99.95 \%$ in permanent magnetic materials [11]. In recent years, the preparation and purification of high-purity rare earth metals has attracted more attention from governments and experts. The relevant departments of the United States, Japan, and other countries have even listed RE products as the key strategic elements for the development of military technology and high technique industries. With the progress of science and technology, high purity rare earth metals play a critical role in national economic construction and daily life [12,13].

\section{Progress in Preparation of Rare Earth Metals}

With the wide applications of rare earth metals, the increasing demand for high-purity rare earth metals has stimulated the rapid development of preparation technology. At present, molten salt electrolysis and metal thermal reduction are the common methods for preparing rare earth metals. In principle, these two methods can extract all kinds of rare earth elements. Light rare earth metals such as $\mathrm{La}, \mathrm{Ce}, \mathrm{Pr}$, and $\mathrm{Nd}$ are produced by molten salt electrolysis for considering economic cost factors such as fixed asset investment, raw materials, and energy consumption [14]. Metal thermal reduction method is more suitable for preparing heavy rare earth metals such as $\mathrm{Gd}, \mathrm{Tb}$, and $\mathrm{Y}$ with high melting and boiling points.

\subsection{Molten Salt Electrolysis}

Several kinds of metals such as $\mathrm{Cu}, \mathrm{Al}$, and $\mathrm{Mg}$ are prepared by molten salt electrolysis [15-17]. The preparation of rare earth metals by molten salt electrolysis started from the molten salt system of chloride. Because of the problems of chloride electrolysis preparation such as easy moisture absorption of raw materials, low yield and serious exhaust pollution, the preparation of rare earth metals by rare earth chloride was clearly banned by the state [18]. Nowadays, rare earth metals are mainly prepared by fluoride oxide electrolysis in industry [19-21]. The schematic diagram of molten salt electrolysis is shown in Figure 1. $\mathrm{RE}_{2} \mathrm{O}_{3}$ dissolved in fluoride molten salt and dissociated into rare earth cations and oxygen anions. Under the action of direct current field, rare earth cations move toward cathode and can be reduced to metals by obtaining electrons [22]. Oxygen anions move to the anode and lose electrons, forming oxygen or interacting with graphite to form $\mathrm{CO}_{2}$ and $\mathrm{CO}$, the reactions that occur in this system are as follows [23]:

$$
\begin{gathered}
\text {-Cathode(reduction) reaction: } \mathrm{RE}^{3+}+3 \mathrm{e}^{-}=\mathrm{RE} \\
\text {-Anode(oxidation) reaction: } 2 \mathrm{O}_{2}-4 \mathrm{e}^{-}=\mathrm{O}_{2}(\mathrm{~g}) \\
\text {-Reduction-oxidation (Redox) reaction: } \mathrm{RE}_{2} \mathrm{O}_{3}+\mathrm{C}=2 \mathrm{RE}+\mathrm{CO}_{2}+\mathrm{CO}
\end{gathered}
$$

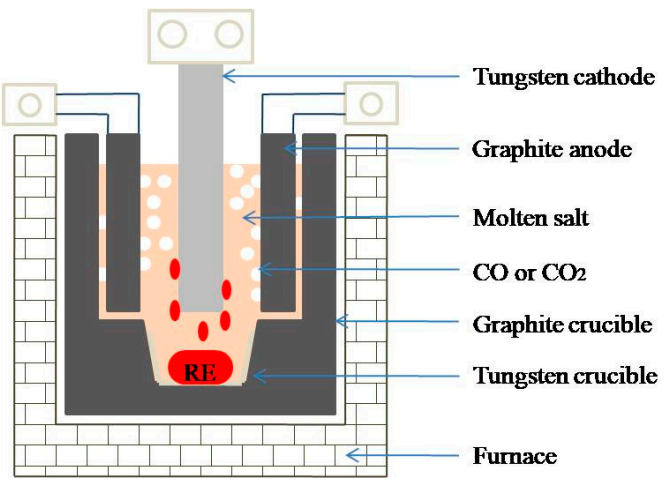

Figure 1. Schematic diagram of molten salt electrolysis. 
Metallic impurities such as $\mathrm{Al}, \mathrm{Si}, \mathrm{Ti}, \mathrm{W}, \mathrm{Mo}$, Fe and interstitial impurities $\mathrm{C}, \mathrm{O}$, and $\mathrm{N}$ might exist in rare earth metals prepared by the above method [24,25].

$\mathrm{Al}$ and Si impurities mainly are derived from furnace materials [26] and raw materials [27]. The concentration of $\mathrm{Al}$ and $\mathrm{Si}$ in rare earth metals were reduced from $0.03 \%$ to below $0.01 \%$ by altering the variety of furnace materials and the purity of raw material [26]. Carbon impurity is mainly related to graphite anode or graphite crucible, and iron impurity mainly came from anode clamp and auxiliary tools [28]. By adjusting electrolytic bath structure, electrolytic temperature and other technical parameters can control the carbon concentration in rare earth metals below $0.03 \%$ and iron concentration below $0.3 \%$ effectively [28,29]. Moreover, $\mathrm{W}$, Ti, and Mo impurities are mainly derived from metal crucible and stirring device. The total concentration of $\mathrm{W}, \mathrm{Ti}$, and Mo could be reduced to below $0.05 \%$ by adjusting the crucible and stirring device materials [30]. Impurities of $\mathrm{O}$ and $\mathrm{N}$ are mainly derived from rare earth oxide and the oxygen in air. The oxygen concentration of commercial electrolysis rare earth metal was even as high as $0.1 \%$ [31]. In recent years, researchers of IMR have explored the oxygen reduction methods in molten salt electrolysis process, and high purity rare earth metals were successfully prepared by regulating technical parameters, as shown on in Figure 2 . At the same time, oxygen concentration could be reduced to less than $0.008 \%$ after using suction casting and airless shot blasting, as shown in Figure 3 [32].
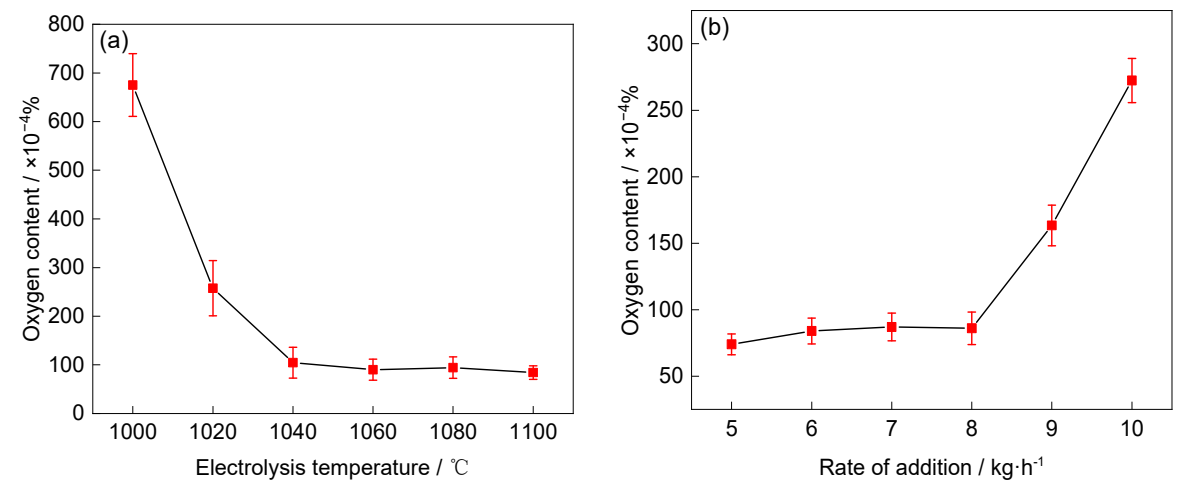

Figure 2. Effect of electrolysis temperature (a) and rate of addition (b) on oxygen concentration.

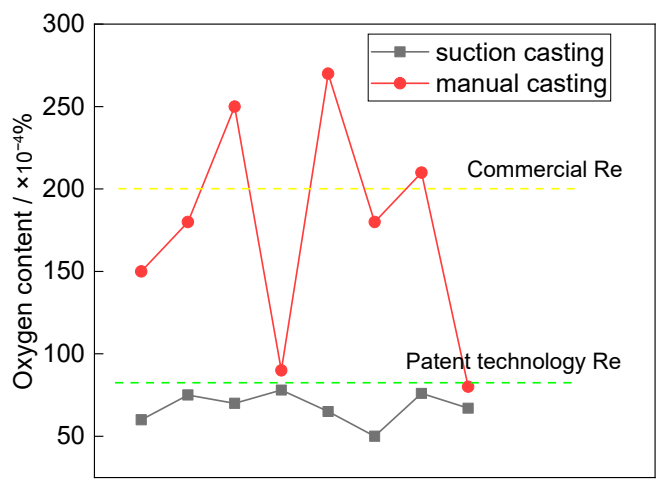

Figure 3. Effect of casting method on oxygen concentration.

Baotou Research Institute of Rare Earths successfully developed a $3 \mathrm{kA}$ fluorosalt system electrolytic bath in 1984. After more than 30 years of development, the scale of electrolytic bath has gradually expanded from 3 to $10 \mathrm{kA}$ [33], and the maximum electrolytic bath could reach $60 \mathrm{kA}$ [34,35]. So far, large-scale rare earth enterprises such as Ruixin Group and Qiandong Group have already used $10 \mathrm{kA}-$ level electrolytic bath [36]. However, because of the low level of automation, most of the rare earth enterprises are still using 6 10 kA electrolytic bath [37]. 


\subsection{Metal Thermal Reduction}

Metal thermal reduction refers to the reduction of rare earth compounds into metals at high temperatures by active metal reducing agents, such as $\mathrm{Ca}$, $\mathrm{La}$, and $\mathrm{Ce}$ [38]. $\mathrm{Sm}, \mathrm{Eu}, \mathrm{Yb}$, and $\mathrm{Tm}$ have moderate melting point and relatively high vapor pressure, so La or Ce with relatively low vapor pressure are used as reductants, the reduction equation is as follows:

$$
2 \mathrm{La}+\mathrm{RE}_{2} \mathrm{O}_{3}=2 \mathrm{RE} \uparrow+\mathrm{La}_{2} \mathrm{O}_{3}
$$

$\mathrm{Y}, \mathrm{Gd}, \mathrm{Tb}, \mathrm{Dy}, \mathrm{Ho}, \mathrm{Er}, \mathrm{Lu}$ are prepared by calcium thermal reduction, the reduction equation is as follows:

$$
3 \mathrm{Ca}+2 \mathrm{ReF}_{3}=3 \mathrm{CaF}_{2}+2 \mathrm{RE}
$$

Metallic impurities such as $\mathrm{Ca}, \mathrm{Ni}, \mathrm{Mo}, \mathrm{Ti}, \mathrm{W}$ and interstitial impurities $\mathrm{C}, \mathrm{O}$, and $\mathrm{N}$ might exist in rare earth metals prepared by the above method [39]. The schematic diagram of metal thermal reduction method is shown in Figure 4.

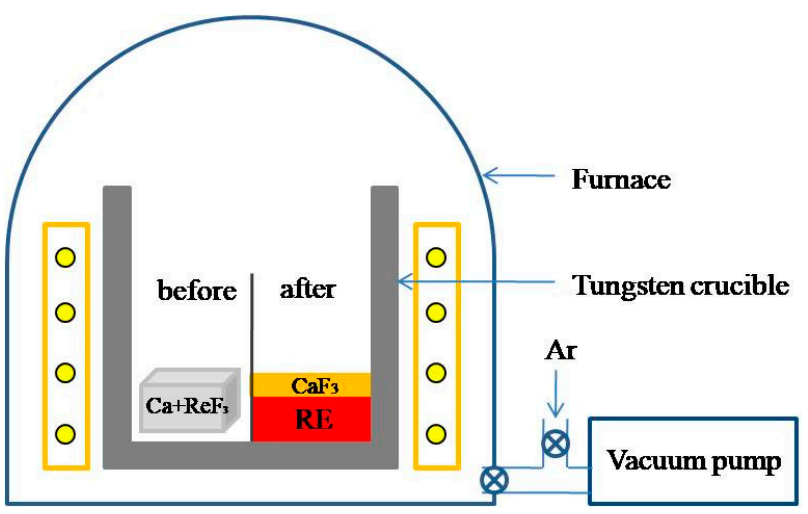

Figure 4. Schematic diagram of metal thermal reduction.

Impurities of rare earth metals are mainly derived from raw materials. Ni impurity mainly came from the nickel boat. Ni concentration could be reduced from $0.01 \%$ to $0.003 \%$ by reducing the temperature of the fluorination process or applying a protective layer on the nickel boat [40]. Impurities such as $\mathrm{Si}, \mathrm{Fe}, \mathrm{Al}, \mathrm{Mo}$, $\mathrm{Ti}$ were mostly from rare earth oxide and reagent materials. Total concentration of impurities in rare earth metals could be reduced from $0.12 \%$ to less than $0.01 \%$ by improving the purity of raw materials as well as using analytical reagent [41]. Oxygen impurity was mainly derived from raw materials, reducing agents, and oxidation of rare earth metals [42,43]. Oxygen concentration could be reduced from $0.1 \%$ to less than $0.07 \%$ by improving the purity of raw materials [40]. Impurities of $\mathrm{W}$ and $\mathrm{Nb}$ were mainly from metal crucible material. Tungsten concentration of rare earth metals could be reduced to less than $0.008 \%$ by improving vacuum remelting or vacuum distillation process conditions [39].

Up to now, single furnace output of metal thermal reduction has gradually developed from $100 \mathrm{~g}$ to $100 \mathrm{~kg}$ [44]. Its advantages are low investment and compact process, but there are also some issues such as harsh requirements on equipment, discontinuous production process, and generally higher impurity concentration than electrolytic rare earth metals.

In conclusion, the researches mainly focused on two aspects: purity and yield. Purity is mainly concerned with reducing metallic impurities such as $\mathrm{Fe}, \mathrm{Mg}$, and $\mathrm{Si}$. The concentration of impurities can be reduced to a certain extent by adjusting the material and technical parameters of the equipment. However, there are fewer studies on effectively reducing the concentration of interstitial impurities such as $\mathrm{O}$ and $\mathrm{N}$, and mechanism of action remain to be further studied. Yield is mainly concerned with low energy consumption and high recovery rate. The gas tightness of equipment and automation degree in preparation process should be more concerned in future. 


\section{Progress in Purification of Rare Earth Metals}

Whether molten salt electrolysis or metal thermal reduction, the purity of rare earth metals is in a range of 95.5 99.5\%, which cannot meet the requirements of high performance materials [45]. At present, the purification methods mainly include vacuum distillation, arc melting, zone melting, and solid state electromigration $[46,47]$.

\subsection{Vacuum Distillation}

In the process of metal thermal reduction, excessive reducing agent is usually added to confirm complete reaction. Therefore, rare earth metals prepared by this method have high impurity concentration and should be purified before application. Vacuum distillation was widely used in industry to remove reductant metals in order to obtain high purity rare earth metals [48-51]. Vacuum distillation means that rare earth metals are separated from impurities under high temperature and high vacuum. Figure 5 shows schematic diagram of vacuum distillation. Vacuum distillation requires that matrix metal should have high saturated vapor pressure and vapor pressure difference from the impurity element. Figure 6 shows the vapor pressures of rare earth elements and impurities at $1600{ }^{\circ} \mathrm{C}$ [52].

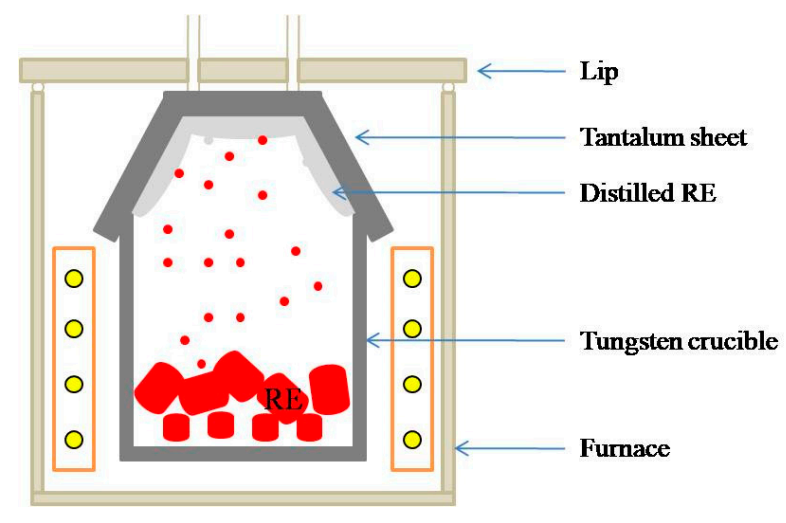

Figure 5. Schematic diagram of vacuum distillation.
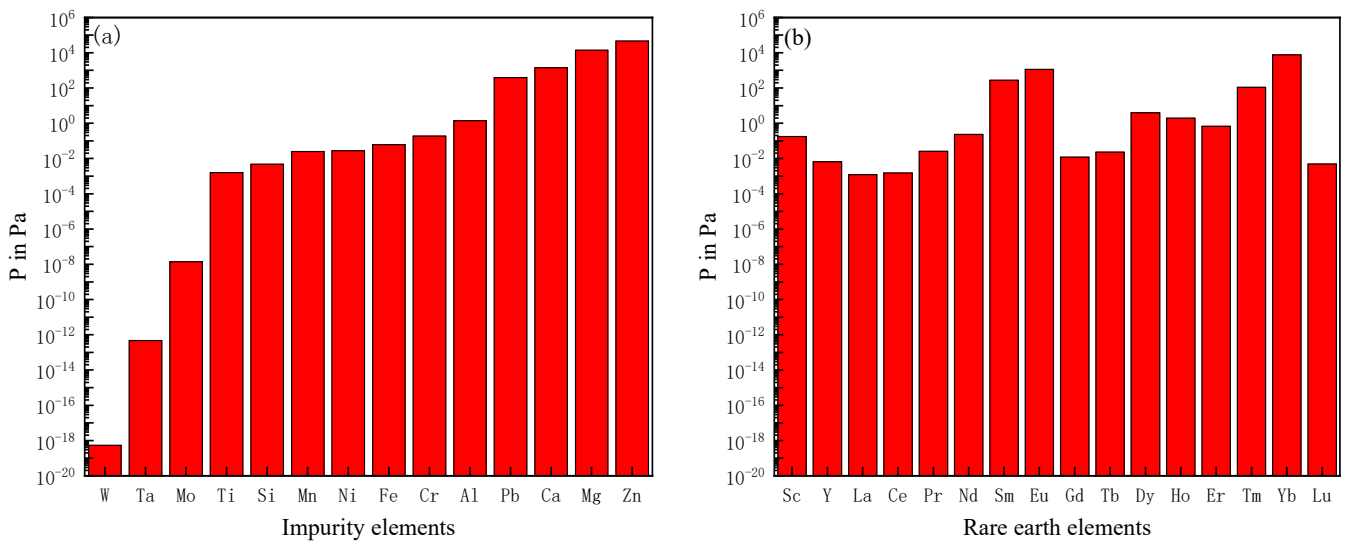

Figure 6. Vapor pressures of impurities (a) and rare earth elements (b) at $1600{ }^{\circ} \mathrm{C}$.

Vacuum distillation can remove most metallic impurities and interstitial impurities. In the process of distillation, metallic impurities with high vapor pressure such as $\mathrm{Ca}, \mathrm{Mg}$, and $\mathrm{Al}$ have obvious removal effect. For example, total concentration of metallic impurities in $\mathrm{Tb}$ such as $\mathrm{Ca}, \mathrm{Mg}, \mathrm{Al}, \mathrm{Si}, \mathrm{Zn}$, $\mathrm{Cr}$, and Mn could be reduced from $0.065 \%$ to less than $0.001 \%$ [53]. Metallic impurities such as Ta, W, $\mathrm{Mo}, \mathrm{Nb}$, and $\mathrm{Ti}$ and interstitial impurities such as $\mathrm{C}, \mathrm{O}$, and $\mathrm{N}$ that exist in the form of compounds remained at the bottom of tungsten crucible [54-56]. This was mainly because the vapor pressure 
of the impurities is much lower than that of the rare earth metals. W concentration of Gd could be reduced from $0.018 \%$ to $0.005 \%$ after vacuum distillation [57]. Interstitial impurity concentration of $\mathrm{Sm}$ was reduced to $0.0045 \%$, and that of $\mathrm{Yb}$ reduced to $0.0051 \%$ [58]. The removal effect of metallic impurities with small vapor pressure difference from matrix metal was not obvious, such as Fe and $\mathrm{Cu}$.

Vacuum distillation has the advantages of relatively high production efficiency and yield, but impurities segregation is prevalent in prepared rare earth metals [59]. Rare earth metal purification by vacuum distillation is still in the stage of small batch trial production, and the single furnace output is only $1 \sim 5 \mathrm{~kg}[60]$.

\subsection{Arc Melting}

Arc melting technology is a common method to purify metals and alloys. It uses electric energy to generate electric arc between electrode and molten material to melt the metal. Metallic impurities with high saturated vapor pressure and interstitial impurities can be effectively removed by using plasma arc as heat source to melt metal materials. At present, the working gas used in this method is mainly $\mathrm{Ar}, \mathrm{H}_{2}, \mathrm{~N}_{2}$, He and the mixture of above gases. In recent years, researchers have found that using the mixture of $\mathrm{Ar}$ and $\mathrm{H}_{2}$ as the working gas could significantly improve the purification effect of rare earth metals. This melting method is called hydrogen plasma arc melting. In the present work, it can be proved that when the temperature reaches $5000 \mathrm{~K}$, the dissociation of $\mathrm{H}_{2}$ is up to above $95 \%$ [61,62]. The activated hydrogen atoms could combine with oxygen and nitrogen. The reactions that occur in this system are as follows:

$$
\begin{gathered}
\mathrm{H}_{2}=\mathrm{H}+\mathrm{H} \\
\mathrm{O}(\text { in metal })+2 \mathrm{H}=\mathrm{H}_{2} \mathrm{O} \\
\mathrm{N}(\text { in metal })+3 \mathrm{H}=\mathrm{NH}_{3}
\end{gathered}
$$

This method has been successfully applied to the purification of rare earth metals such as $\mathrm{La}, \mathrm{Ce}$, $\mathrm{Tb}$, and $\mathrm{Gd}[63,64]$. Figure 7 is the schematic diagram of hydrogen plasma arc melting.

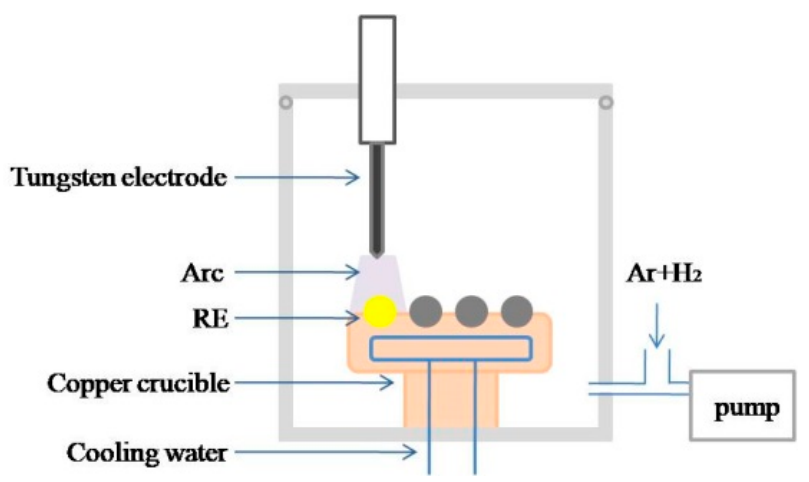

Figure 7. Schematic diagram of hydrogen plasma arc melting.

Metallic impurities with high saturated vapor pressure such as $\mathrm{Ca}, \mathrm{Mg}$, and $\mathrm{Al}$ could be effectively removed by arc melting. For example, total concentration of metallic impurities of $\mathrm{Tb}$ decreased from $0.438 \%$ to $0.0580 \%$ after arc melting [63]. Hydrogen plasma has high chemical reactivity. It can react with carbon, oxygen, nitrogen, and other impurities to form gaseous compounds, thus promoting impurities clearance [65]. When $\mathrm{Tb}$ and $\mathrm{LaNi}_{5}$ alloy were melted in hydrogen plasma, carbon concentration of $\mathrm{Tb}$ decreased from $0.03 \%$ to $0.0017 \%$ [63], and carbon concentration of $\mathrm{LaNi}_{5}$ alloy decreased from $0.018 \%$ to $0.0014 \%$ [64]. The concentration of $\mathrm{O}$ and $\mathrm{N}$ of $\mathrm{Tb}$ decreased from $0.05 \%$ to $0.0015 \%$ [66].

Hydrogen plasma arc melting have a good removal effect on metallic impurities and interstitial impurities. The removal degree of interstitial impurities is obviously better than other methods. However, because of high temperature and high vacuum required by the process, hydrogen plasma arc 
melting technology for rare earth metals is still in the laboratory research stage, and its single furnace output is only 10 200 $\mathrm{g}[67,68]$.

\subsection{Zone Melting}

Zone melting is a process of redistributing impurities by making use of their different solubility in solid and liquid phases. In this operation, the researchers slowly melt the metal bar by moving the induction coil from one end of the metal bar to the other. This process allows multiple directional movements to accumulate impurities at both ends of the metal bar. Equilibrium distribution coefficient refers to the ratio of solute concentration in the solid and liquid phases when the solid and liquid systems reach equilibrium [69], and defined as:

$$
\mathrm{K}=\mathrm{C}_{\mathrm{S}} / \mathrm{C}_{\mathrm{L}}
$$

where $C_{S}$ and $C_{L}$ are denoted as impurity concentration in solid phase and impurity concentration in the liquid phase respectively. Impurities whose $K<1$ move toward the end of the metal bar, and impurities whose $K>1$ move toward the beginning end of the metal bar. Figure 8 is the schematic diagram of plasma arc zone melting.

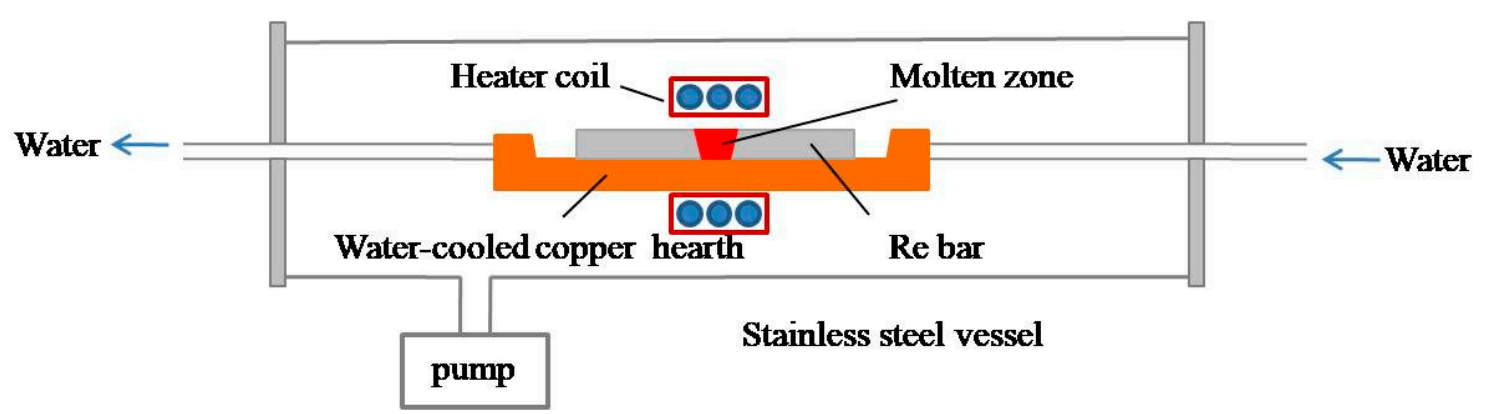

Figure 8. Schematic diagram of plasma arc zone melting.

Zone melting has been widely used to purify semiconductor materials such as $\mathrm{Si}, \mathrm{Sb}, \mathrm{Te}$, and metal materials such as $\mathrm{Zn}$ and $\mathrm{Cu}$ [70]. Researchers have applied zone melting to purify rare earth metals, and the results showed that there were obvious segregation in the rare earth metals [71]. Metallic impurities with high saturated vapor pressure such as $\mathrm{Ca}, \mathrm{Mg}, \mathrm{Zn}, \mathrm{Mn}$ could be reduced to less than $0.0001 \%$. Fe, $\mathrm{Cu}, \mathrm{Al}, \mathrm{Si}$ could be enriched at the end as the melted zone moves [72]. Interstitial impurities such as $\mathrm{O}$ and $\mathrm{N}$ were enriched at the beginning [73]. Impurities such as $\mathrm{C}$ and $\mathrm{S}$ showed different migration patterns in different rare earth metals. After zone melting, impurities such as $C$ and $S$ of La were enriched at the beginning, while $C$ and $S$ of Ce were enriched at the end [73].

Zone melting had obvious migration effect on some metallic impurities and interstitial impurities. However, different migration rules of impurities usually appeared in different rare earth metals, and the purification mechanism needs to be further studied. The principle of zone melting is the redistribution of impurities rather than actual removal of impurities. In order to achieve excellent purification effect, nearly 20 times of repeated melting of rare earth metals are needed. Moreover, the purification efficiency of zone melting is low, and the single furnace output of rare earth metals is only about $30 \mathrm{~g}$. Therefore, zone melting is only used as the final method to purify small batches of high purity rare earth metals $[73,74]$.

\subsection{Solid State Electromigration}

Solid state electromigration means that under high vacuum conditions, the metal bar is placed between two electrodes and applied with direct current for a long time. The joule heat make the temperature of the test bar reach 0.8 0.9 times of the metal melting point and keep the test bar from 
melting. Under the action of direct current, atoms are not neutral. In general, one atom can acquire more or less positive charge than the other, resulting in different ionization behaviors. Moreover, atoms can be affected by electrostatic force, electron collision friction and cavity friction [75], and defined as:

$$
\begin{gathered}
F_{S}=e E Z^{0} \\
F_{e}=-e E n_{e} l_{e} \sigma_{e} \\
F_{h}=e E n_{h} l_{h} \sigma_{h} \\
F=F_{S}+F_{e}+F_{h}=e E Z^{0}-e E n_{e} l_{e} \sigma_{e}+e E n_{h} l_{h} \sigma_{h}=e E Z^{*}
\end{gathered}
$$

where e is elementary charge in units of $C$; $E$ is electric field intensity in units of $\mathrm{V} \cdot \mathrm{m}^{-1} ; Z^{0}$ is the ion valence; $\mathrm{n}$ is unit volume electron; 1 is the electron mean free path; $\sigma$ is the electron scattering cross section; $Z^{*}$ is effective valence.

Atoms with more positive charge migrate to the cathode extreme, and atoms with more negative charge migrate to the anode extreme. In the purification process, the migration rate of impurity atoms is higher than that of matrix atoms, so the impurities can be redistributed in matrix metal. Metals exhibit different crystal structures at different temperatures. Interstitial impurities show different migration patterns in different crystal structures. For example, when Pr is in double hexagonal closest packed structure (named as DHCP), H, N, and $\mathrm{O}$ atoms can enter the intercellular space except C. However, when Pr is transformed into BCC structure, all atoms cannot enter the intercellular space except H [76]. Therefore, researchers attempt to remove interstitial impurities by solid state electromigration at crystal temperature with a high migration rate of interstitial impurities $[77,78]$. Figure 9 is the schematic diagram of rare earth prepared by solid state electromigration.

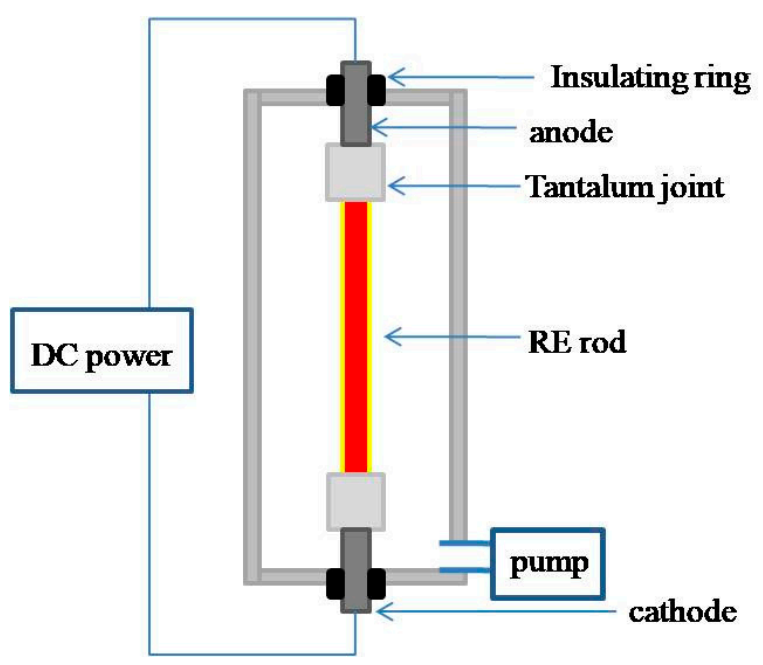

Figure 9. Schematic diagram of solid state electromigration.

For example, after $216 \mathrm{~h}$ of high vacuum and high temperature electromigration, the concentration of impurities such as $\mathrm{Al}$ and $\mathrm{Si}$ of Pr decreased from $0.04 \%$ to $0.02 \%$, and total concentration of Fe and Ni decreased from $0.05 \%$ to $0.002 \%$ [79]. The concentration of interstitial impurities was reduced from $0.0239 \%$ to $0.0049 \%$, among which the oxygen concentration was reduced to $0.0022 \%$ [80]. Solid state electromigration had significant removal effect on most metallic impurities and interstitial impurities [81], but not obvious removal effect on carbon and nitrogen impurities [82,83]. Solid state electromigration was essentially a process of impurities redistribution, and it did not really remove impurities, which will seriously affect the subsequent use of rare earth metals. Since the solid state electromigration process required high vacuum degree and energy consumption of equipment. It is 
difficult to achieve large-scale industrial production, so this method is mainly used as the final purification method to produce small amount of ultra-high purity metals [84].

From the above, it is not possible to remove all impurities of rare earth metals simultaneously by any of the above methods. Therefore, after comprehensive consideration of the impurity types, purity requirements and removal effect of impurities, it should be considered that several purification methods should be combined to remove the impurities. For example, vacuum distillation combined with arc melting can improve the density and purity of rare earth metals. Ultralow oxygen concentration of rare earth metals can be prepared by the combination of arc melting and solid state electromigration.

\section{Summary and Prospect}

In the past 60 years of development, remarkable achievements have been achieved in scientific research and industrial application of rare earth elements, forming a relatively well-developed rare earth industrial system. But at the same time, it should also be noted that there are issues in many areas that need to be solved.

(1) Molten salt electrolysis and metal thermal reduction possess high efficiency and yield, but low purity of rare earth metals and high energy consumption are generally non-negligible.

(2) The preparation process of rare earth metals is mainly a manual operation with low automation degree and severe environmental pollution issue.

(3) Deep purification ability of rare earth metals is insufficient, and the industrialization is limited to the use of vacuum distillation, which is difficult to meet the needs of high technology development.

Consequently, expensive price of high-purity rare earth metals appeared and limit their application. Therefore, the following directions are the focus of our attention in future:

(1) The impurity concentration of rare earth metal should be further reduced so as to provide high purity starting material for the purification process.

(2) A combination of various purification methods should be chosen to remove the impurities for considering the kinds and uses of rare earth metals.

(3) Purification methods suitable for mass production such as vacuum levitation melting and electron beam melting should be developed and researched.

Author Contributions: Conceptualization, H.L. and Y.L.; methodology, H.L. and Y.L.; software, H.L.; validation, H.Y.; formal analysis, H.L.; investigation, H.L.; resources, D.L.; data curation, H.Y.; writing-original draft preparation, H.L.; writing-review and editing, H.Y.; visualization, Y.Z.; supervision, Y.L. and D.L.; project administration, Y.Z.; funding acquisition, Y.L. All authors have read and agreed to the published version of the manuscript.

Funding: This research was supported by Strategic Priority Research Program of the Chinese Academy of Sciences funded by Chinese Academy of Sciences (ACS) (XDC04010200). This work was also supported by Inner Mongolia Science and Technology Major Project funded by Inner Mongolia Science and Technology Department (2017B001).

Conflicts of Interest: The authors declare no conflict of interest.

\section{References}

1. O'Keefe, M.J.; Geng, S.J.; Joshi, S. Cerium-based conversion coatings as alternatives to hex chrome: Rare-earth compounds provide resistance against corrosion for aluminum alloys in military applications. Met. Finish. 2007, 105, 25-28. [CrossRef]

2. Ji, L.Q.; Chen, M.X.; Gu, H. Actuality of Light Rare Earth Resources and Application in Field of New Energy Vehicles. J. Chin. Rare Earths Soc. 2020, 38, 129-138. (In Chinese)

3. Abdouli, K.; Cherif, W.; Omrani, H. Structural magnetic and magnetocaloric properties of La0.5Sm0.2Sr0.3Mn1-xFexO3 compounds with $(0 \leq x \leq 0.15)$. J. Magn. Magn. Mater. 2019, 457, 635-642. [CrossRef] 
4. Yang, C.Y.; Liu, P.; Luan, Y.K. Study on transverse-longitudinal fatigue properties and their effective-inclusion-size mechanism of hot rolled bearing steel with rare earth addition. Int. J. Fatigue 2019, 128, 105193. [CrossRef]

5. Ma, B.M.; Herchenroeder, J.W.; Smith, B. Recent development in bonded NdFeB magnets. J. Magn. Magn. Mater. 2002, 239, 418-423. [CrossRef]

6. Cui, J.; Kramer, M.; Zhou, F. Current progress and future challenges in rare-earth-free permanent magnets. Acta Mater. 2018, 158, 118-137. [CrossRef]

7. EHsu, S.; MBeibutian, V.; TYeh, M. Preparation of hydrogen storage alloys for applications of hydrogen storage and transportation. J. Alloys Compd. 2002, 330, 882-885.

8. Yang, C.Y.; Luan, Y.K.; Li, D.Z. Effects of rare earth elements on inclusions and impact toughness of high-carbon chromium bearing steel. J. Mater. Sci. Technol. 2019, 35, 1298-1308. [CrossRef]

9. Li, H.H.; Liu, X.; Li, Y. Effects of rare earth Ce addition on microstructure and mechanical properties of impure copper containing Pb. Trans. Nonferr. Met. Soc. China 2020, 30, 1574-1581. [CrossRef]

10. Wu, B.H.; Ding, X.F.; Zhang, Q.K. The dual trend of diffusion of heavy rare earth elements during the grain boundary diffusion process for sintered Nd-Fe-B magnets. Scr. Mater. 2018, 148, 29-32. [CrossRef]

11. Wang, Z.Q.; Wu, D.G.; Zhang, X.W. Rare Earth Metal Targets and Their Preparation Methods. Chinese Patent 106637100B, 1 May 2017. (In Chinese).

12. Zhang, M.; Shen, B.G.; Hu, F.X. A Mixed Rare Earth-Iron-Based Permanent Magnetic Material and a Preparation Method and Application. Chinese Patent 107578869B, 17 March 2020. (In Chinese).

13. Yang, C.Y.; Luan, Y.K.; Li, D.Z. Very high cycle fatigue behavior of bearing steel with rare earth addition. Int. J. Fatigue 2020, 131, 105263. [CrossRef]

14. Kobisk, E.H.; Grisham, W.B. Application of reduction-distillation method for preparing high-purity rare-earth isotope metals. Mater. Res. Bull. 1969, 4, 651-662. [CrossRef]

15. Zhang, J.; Fang, S.; Qi, X.P. Preparation of high-purity straight silicon nanowires by molten salt electrolysis. J. Energ. Chem. 2020, 40, 171-179. [CrossRef]

16. Yan, B.L.; Wang, J.; Yang, T. Synthesis of Ti powders with different morphologies via controlling the valence state of the titanium ion in $\mathrm{KCl}-\mathrm{NaCl}$ molten salt. J. Electroanal. Chem. 2020, 876, 114496. [CrossRef]

17. Zhou, Z.R.; Zhang, Y.J.; Hua, Y.X. Molten salt electrolytic synthesis of silicon-copper composite nanowires with enhanced performances as lithium ion battery anode. J. Alloys Compd. 2018, 751, 307-315. [CrossRef]

18. Chen, G.H.; Liu, Y.B. Research progress of rare earth molten salt electrolysis technology. Rare Earth Inf. 2015, 379, 15-18. (In Chinese)

19. Cai, B.F.; Liu, H.L.; Kou, F. Estimating perfluorocarbon emission factors for industrial rare earth metal electrolysis. Resour. Conserv. Recycl. 2018, 136, 315-323. [CrossRef]

20. Zhu, X.P.; Sun, S.C.; Liu, C. Solubility of $\mathrm{RE}_{2} \mathrm{O}_{3}(\mathrm{RE}=\mathrm{La}$ and $\mathrm{Nd})$ in light rare earth fluoride molten salts. J. Rare Earths 2018, 36, 765-771. [CrossRef]

21. Kaneko, A.; Yamamoto, Y.; Okada, C. Electrochemistry of rare earth fluoride molten salts. J. Alloys Compd. 1993, 193, 44-46. [CrossRef]

22. Arwin, G. Thermodynamic Considerations in Molten Salt Electrolysis for Rare Earth Metals. Master's Thesis, Montana Tech of the University of Montana, Butte, MT, USA, 2015.

23. Vogel, H.; Flerus, B.; Stoffner, F. Reducing greenhouse gas emission from the neodymium oxide electrolysis. J. Sustain. Met. 2017, 6, 99-107. [CrossRef]

24. Chen, Y.Q. Research Progress of Preparation of Rare Earth Metals by Electrolysis in Fluoride Salt System. Rare Earths 2014, 35, 99-107. (In Chinese)

25. Lu, X.N.; Zhang, X.Z.; Xie, X.R. On the effective control of non-rare earth impurity in the preparation of praseodymium neodymium alloy by 25 kA molten salt electrolysis. Nonferr. Met. Sci. Eng. 2015, 6, 10-15. (In Chinese)

26. Liu, J.G. Improvement on Molten Salt Electrolytic Furnace for Preparing Rare Earth. Guangdong Chem. Ind. 2015, 42, 59. (In Chinese)

27. Zhou, A.G.; Chen, Y.X.; Peng, S.H. Effects of Silicon on Pr-Nd Alloy Production by Molten Salt Electrolytic Method. China Tungsten Ind. 2012, 27, 44-46. (In Chinese)

28. Liu, M.G.; Wang, L.L. Study on the Effects of Electrolysis Temperature on Technical Indexes of Rare Earth Electrolytic Cell. Rare Met. Cem. Carb. 2014, 42, 16-19. (In Chinese) [CrossRef] 
29. Wan, J.; Chen, H.B.; Mi, X.X. Carbon Content Control for Pr-Nd Alloy Production Process Using 6000A Electrolysis Cell. Mater. China 2008, 27, 41-43. (In Chinese)

30. Chen, G.H.; Cao, Y.C.; Liu, Y.B. Preparation of Pr-Nd-Gd Alloys by Molten Salt Electrolysis. J. Chin. Rare Earth Soc. 2015, 33, 206-210. (In Chinese)

31. Zhang, Z.Q.; Wang, Z.Q.; Chen, D.H.; Miao, R.Y.; Zhu, Q.; Zhang, X.W.; Zhou, L.; Li, Z.A. Purification of praseodymium to $4 \mathrm{~N} 5+$ purity. Vacuum 2014, 102, 67-71. [CrossRef]

32. Fu, P.X.; Liu, H.W.; Luan, Y.K. A Method for Preparing High Purity La and Ce Mixed Rare Earth by Electrolysis. Chinese Patent 106894056B, 10 July 2018. (In Chinese)

33. Gong, Y.T.; Li, Y.Z.; Pang, Q.S. Effect of Multiple Factors on Electrolysis Efficiency of Rare Earth Electrolyzer. Nonferr. Met. 2019, 9, 53-58. (In Chinese)

34. Liu, Z.X.; Dong, Y.F.; Wu, Y.F. Numerical Simulation of Effect of Anode Inclination on the Flow of the Molten Salt in 60kA Bottom-cathode Rare Earth Electrolytic Cell. Chin. Rare Earth 2013, 34, 21-24. (In Chinese)

35. Wu, Y.F.; Zhang, X.J.; Chen, S.Q. Numerical Simulation of Electric Field in 60kA Immersion Rare Earth Electrolytic Cell. Nonferr. Met. (Extr. Met.) 2015, 2, 31. (In Chinese)

36. Pang, S.M.; Yan, S.H.; Li, Z.A. Development on Molten Salt Electrolytic Methods and Technology for Preparing Rare Earth Metals and Alloys in China. Rare Met. 2011, 35, 440-450. (In Chinese)

37. Liu, Y.B.; Chen, G.H.; Yu, B. Research Progress of Tapping Technology for Molten Salt Electrolytic Preparation of Rare Earth Metals. Chin. Rare Earth 2018, 39, 134-140. (In Chinese)

38. Wang, X.S.; Wang, Z.Q.; Chen, D.H. Development and Status quo of Rare Earth Metals Preparation Technologies. Chin. Rare Earths 2015, 36, 123-132. (In Chinese)

39. Cheng, W.; Hang, M.S.; Wang, Z.J. Preparation of High-purity Lanthanum by Calciothermic Reduction. Min. Met. Eng. 2013, 3, 104. (In Chinese)

40. Wu, J.S.; Chen, H.Q.; Zuo, J.X. Method for reducting non-RE impurities in pure Tb. Rare Met. Cem. Carb. 1999, 2, 3-5. (In Chinese)

41. Lei, B.C.; Liu, B. Technology investigation of making high-pure metal terbium. Sichuan Nonferr. Met. 2000, 2, 53-56. (In Chinese)

42. Li, G.L.; Li, L.; Hao, J. Investigation of oxygen diffusion behavior in terbium using $18 \mathrm{O}_{2}$ isotopic tracking by high resolution SIMS. Mater. Lett. 2016, 176, 253-256. [CrossRef]

43. Tang, D.X. Rare Earth Metal Materials; Metallurgical Industry Press: Beijing, China, 2011; p. 21.

44. Liu, Y.J.; Yan, S.H. Development of rare earth pyrometallurgical technology in China. Rare Earth Inf. 2003, 4, 2-8. (In Chinese)

45. Zhao, E.X.; Luo, G.P.; Zhang, X.H. Preparation methods of high purity rare earth metals and the latest development trend. Met. Funct. Mater. 2019, 26, 47-52. (In Chinese)

46. Isshiki, M.; Mimura, K.; Uchikoshi, M. Preparation of high purity metals for advanced devices. Thin Solid Films 2011, 519, 8451-8455. [CrossRef]

47. Waseda, Y.; Isshiki, M.; Johnston, S. Purification process and characterization of ultra high purity metals. Mater. Technol. 2002, 17, 192. [CrossRef]

48. Zhang, L.; Zhang, X.W.; Li, Z.A. Distribution model of highly volatile impurity in distillate of rare earth metal. Vacuum 2020, 176, 109307. [CrossRef]

49. Hai, Z.Z.; Xu, L.C. Preparation of Metal Samarium by Direct Reduction-Distillation of Samarium-Gadolinium Enrichment. Nonferr. Met. (Extr. Met.) 2018, 3, 69-73. (In Chinese)

50. Busch, G.; Kaldis, E.; Muheim, J. The purification of europium. J. Less Common Met. 1971, $24,453-457$. [CrossRef]

51. Ionov, A.M.; Nikiforova, T.V.; Rytus, N.N. Aspects of the purification of volatile rare earth metals by UHV sublimation: Sm, Eu, Tm, Yb. Vacuum 1996, 47, 879-883. [CrossRef]

52. Yaws, C.L.; Marco, A.; Satyro. Chapter 2-Vapor Pressure-Inorganic Compounds. In The Yaws Handbook of Vapor Pressure; Elsevier: Amsterdam, The Netherlands, 2015; pp. 315-322.

53. Li, G.L.; Li, L.; Miao, R.Y. Research on the removal of impurity elements during ultra-high purification process of terbium. Vacuum 2016, 125, 21-25. [CrossRef]

54. Hirota, K.; Okabe, T.H.; Saito, F. Electrochemical deoxidation of RE-O (RE = Gd Tb Dy Er) solid solutions. J. Alloys Compd. 1999, 282, 101-108. [CrossRef] 
55. Okabe, T.H.; Hirota, K.; Kasai, E. Thermodynamic properties of oxygen in RE-O (RE = Gd, Tb, Dy, Er) solid solutions. J. Alloys Compd. 1998, 279, 184-191. [CrossRef]

56. Zhang, Z.Q.; Wang, Z.Q.; Miao, R.Y.; Zhu, Q.; Chen, D.H.; Zhang, X.W.; Zhou, L.; Li, Z.G.; Yan, S.H. Purification of yttrium to $4 \mathrm{~N} 5+$ purity. Vacuum 2014, 107, 77-82. [CrossRef]

57. Zhang, X.Q.; Jiang, Y.J.; Dai, Q. Preparation of high purity matallic gadolinium by the vacuum distillation Method. Sci. Technol. Baotou Steel 2007, 33, 17-20. (In Chinese)

58. Zhang, X.W.; Wang, Z.Q.; Chen, D.H. Preparation of high purity rare earth metals of Samarium, Ytterbium and Thulium. Rare Met. Mater. Eng. 2016, 45, 2793-2797.

59. Zhang, X.W.; Miao, R.Y.; Li, C.J. Impurity distribution in metallic dysprosium during distillation purification. J. Rare Earths 2016, 34, 924-930. [CrossRef]

60. Zhang, X.W.; Miao, R.Y.; Wu, D.G. Impurity distribution in distillate of terbium metal during vacuum distillation purification. Trans. Nonferr. Met. Soc. China 2017, 27, 1411-1416. [CrossRef]

61. Dembovsky, V. Plasmametallury, Materials Science Monograph; Elsevier Science: Prague, Czech Republic, 1985.

62. McGee, H.A. Electric Propulsion Development; Academic Press: New York, NY, USA, 1963.

63. Li, G.L.; Guo, H.; Li, L.; Wang, C.Y. Purification of terbium by means of argon and hydrogen plasma arc melting. J. Alloys Compd. 2016, 659, 1-7. [CrossRef]

64. Li, G.L.; Li, L.; Guo, H. Effect of Plasma Arc Melting Technology on Carbon Concentration in Terbium. High Vol. Eng. 2015, 41, 2925-2929. (In Chinese)

65. Wang, H.B.; Wang, S.M.; Wu, Y.F. Preparation of high purity $\mathrm{LaNi}_{5}$ alloy with low carbon content by hydrogen plasma arc melting. Chin. Rare Earth 2019, 40, 24-31. (In Chinese)

66. Fu, K.; Li, G.L.; Li, J.G. Study on the thermodynamics of the gadolinium-hydrogen binary system $(\mathrm{H} / \mathrm{Gd}=0.0-2.0)$ and implications to metallic gadolinium purification. J. Alloys Compd. 2016, 673, 131-137. [CrossRef]

67. Li, G.L.; Li, L.; Yang, C. Removal of gaseous impurities from terbium by hydrogen plasma arc melting. Int. J. Hydrog. Energy 2015, 40, 7943-7948. [CrossRef]

68. Li, L.; Li, G.L.; Xu, L. A new process of manufacturing “oxygen-free" Gd. Rare Met. Mater. Eng. 2016, 45, 2509-2512. [CrossRef]

69. Ren, Y.S.; Li, J.; Duan, X.X. Determination of Equilibrium Distribution Coefficients of Impurities in Phosphorus by Vertical Zone-melting Technique. Chin. J. Chem. Eng. 2011, 19, 223-226. [CrossRef]

70. Yu, W.Z.; Yang, X.; Jie, M. Segregation and removal of transition metal impurities during the directional solidification refining of silicon with Al-Si solvent. J. Alloys Compd. 2019, 15, 198-204. [CrossRef]

71. Fort, D.; Jones, D.W. Zone refining of rare earth metals: Lanthanum, cerium, and Gadolinium. J. Less Common Met. 1998, 81, 273-292. [CrossRef]

72. Jun, H.; Ren, Q.B.; Hu, Z.Q. Application of a Genetic Algorithm to Optimize Redistribution Process in Zone Refining of Cerium. Rare Met. Mater. Eng. 2017, 46, 3633-3638. [CrossRef]

73. Fort, D.; Beaudry, B.J.; Gschneidner, K.A. The ultra purification of rare earth metals: Gadolinium and neodymium. J. Less Common. Met. 1987, 134, 27-44. [CrossRef]

74. Mimura, K.; Sato, T.; Isshiki, M. Purification of lanthanum and cerium by plasma arc zone melting. J. Mater. Sci. 2008, 43, 2721-2730. [CrossRef]

75. Ho, P.S.; Kwok, T. Electromigration in metals. Rep. Prog. Phys. 1989, 52, 301-348. [CrossRef]

76. Muirhead, C.M.; Jones, D.W. The purification of the rare-earth metals: III. Solid state electrotransport processing of praseodymium. J. Less Common Met. 1976, 50, 73-83. [CrossRef]

77. Chiu, Y.T.; Lin, K.L.; Wu, A.T. Electrorecrystallization of Metal Alloy. J. Alloys Compd. 2013, 549, $190-194$. [CrossRef]

78. Minoru, I. Purification of rare earth metals. Vacuum 1996, 47, 885-887.

79. Fu, S.; Li, Z.; Zhang, Z.Q. Purification of Praseodymium by Solid State Electrotransport. Rare Met. 2015, 39, 1018-1023. (In Chinese)

80. Li, Z.A.; Chen, D.H.; Wang, Z.Q. Purification of Gadolinium by Solid State Electrotransport Processing. J. Chin. Rare Earth Soc. 2012, 30, 693-698. (In Chinese)

81. Fort, D.; Pecharsky, V.K. Solid state electrotransport purification of dysprosium. J. Alloys Compd. 1995, 226, 190-196. [CrossRef] 
82. Lonov, A.M.; Volkov, V.T.; Nikiforova, T.V. Behaviour of interstitial impurities on the surface of yttrium during solid state electrotransport: Auger studies. J. Alloys Compd. 1995, 223, 91-96.

83. Long, K.C. Preparation and purification of rare earth metals. Rare Met. Mater. Eng. 1991, 2, 1-8. (In Chinese)

84. Miao, R.Y.; Zhang, X.Y.; Zhu, Q. Impurities especially titanium in the rare earth metal gadolinium-before and after solid state electrotransport. J. Rare Earths 2014, 32, 1073-1079. [CrossRef]

Publisher's Note: MDPI stays neutral with regard to jurisdictional claims in published maps and institutional affiliations.

(C) 2020 by the authors. Licensee MDPI, Basel, Switzerland. This article is an open access article distributed under the terms and conditions of the Creative Commons Attribution (CC BY) license (http://creativecommons.org/licenses/by/4.0/). 